\title{
Antihyperlipidemic Activity of Murraya koenigii Leaves Methanolic and Aqueous Extracts on Serum Lipid Profile of High Fat-Fructose Fed Rats
}

\author{
Rohan S. Phatak ${ }^{1, *}$, Chitra C. Khanwelkar', Somnath M. Matule', Kailas D. Datkhile ${ }^{2}$, Anup S. Hendre ${ }^{3}$
}

Rohan S. Phatak ${ }^{1, *}$, Chitra C. Khanwelkar' ${ }^{1}$, Somnath M. Matule', Kailas D. Datkhile², Anup S. Hendre ${ }^{3}$

'Department of Pharmacology, Krishna Institute of Medical Sciences, Karad-415110 Maharashtra, INDIA.

${ }^{2}$ Department of Molecular Biology and Genetics, Krishna Institute of Medical Sciences, Karad-415110, Maharashtra, INDIA.

${ }^{3}$ Department of Biochemistry, Krishna Institute of Medical Sciences, Karad-415110, Maharashtra, INDIA.

\section{Correspondence}

\section{Rohan S. Phatak}

Department of Pharmacology,

Krishna Institute of Medical Sciences,

Karad-415110, Maharashtra, INDIA.

E-mail: phatak.rohan1983@gmail.com

History

- Submission Date: 10-01-2019;

- Review completed: 30-03-2019;

- Accepted Date: 10-05-2019.

DOI : 10.5530/pj.2019.11.134

Article Available online

http://www.phcogj.com/v11/i4

Copyright

(c) 2019 Phcogj.Com. This is an openaccess article distributed under the terms of the Creative Commons Attribution 4.0 International license.

\begin{abstract}
Background: Dyslipidemia has been considered as one of coronary risk factors contributing to the cardiovascular diseases. The beneficial effects of Murraya koenigii leaf on HFFD induced hyperlipidemia in rats has been very less reported in the recent review of literature. Aim and Objectives: To study the hypolipidemic activity of Murraya koenigii leaves on the serum lipid profile in HFFD rat model. Material and Methods: Thirty-six rats of either sex were randomly divided into six groups of six animals each. HFFD was fed p.o to all rats from Groups I, II, IV, V and VI except Group III throughout the period of 14 weeks. Group III rats received normal diet and water ad libitum only. Group I, II, IV and V were treated respectively with AEMK (200 mg/kg/day, p. o), MEMK (200 mg/kg/day, p. o), MET (50 mg/kg/day, p. o) and ATO (10 $\mathrm{mg} / \mathrm{kg} /$ day, p. o). On the last day of experimental study, blood was collected by retro-orbital puncture method. BSL and lipid profile were assessed. Results: Elevated levels of TC, TG, LDL-C, VLDL-C and diminished level of HDL-C were observed in group VI. Murraya koenigii leaves extract exhibited significant hypolipidemic effect on serum TC and LDL-C in rats owing to its hypocholesterolemic properties. AIP was highly significant in both of AEMK and MEMK extracts. Conclusion: Results of the present study have suggested that the antihyperlipidemic activity of Murraya koenigii leaves leading to decrease in serum lipid parameters mainly TC, LDL-C along with atherogenic risk might be due to its presence of bioactive compounds.

Key words: High fat-fructose diet, Murraya koenigii, Hyperlipidemia, Lipid profile, Atherogenic index.
\end{abstract}

\section{INTRODUCTION}

Changing lifestyle is associated with high prevalence of stress, lack of physical exercise, high consumption of fat-enriched junk foods and high fructose/glucose containing soft drinks. All of these contributing factors may add to MetS. ${ }^{1}$ MetS is defined as a bunch of several metabolic disorders including hypertension, insulin resistance, dyslipidemia, diabetes and cardiovascular disease. Management of dyslipidemia in early stages may lead to the progression of hepatic steatosis. ${ }^{2}$ Obesity has become a global health problem and leads to the development of chronic diseases like CHD, dyslipidemia and type II diabetes, pancreatic $\beta$-cell dysfunction or overtiredness of pancreas is primarily related with resistance to insulinmediated peripheral glucose disposal and thus leads to hyperinsulinemia. ${ }^{1,3}$

Type 2 diabetes mellitus is a well-known high risk factor for atherosclerotic and CVD that confers a markedly increased risk of $\mathrm{CHD}$ and cardiovascular mortality when compared to non-diabetic patients. ${ }^{4}$ Atherosclerosis is CVD characterized by the deposition of lipids in the artery wall and the infiltration of inflammatory cells, such as monocytes and lymphocytes. ${ }^{4}$ Phenotypic changes in vascular SMC occur in diabetes and it leads to increased contractility, cellular proliferation, migration and extracellular matrix formation. ${ }^{4,5}$ Accelerated SMC causes to the atherosclerotic plaque development. ${ }^{5}$ So, the clear mechanism is still poorly understood behind how diabetes accelerates atherosclerotic CVD.

Phytoestrogens are group of plant derived analogues that mimic the actions of mammalian estrogen, $17 \beta$-estradiol structurally and functionally bind to estrogen receptor and induce production of SHBG in the liver and affects sexual hormone metabolism. ${ }^{6}$ Decline in estrogen hormone is also one of many contributing factors in the CVD. ${ }^{7}$ HMG-CoA reductase inhibitors are well known drugs in the management and prevention of hyperlipidemia and lipid-related disorders. Statins like atorvastatin, rosuvastatin and pitavastatin are being selective inhibitors of HMG-CoA reductase which is ratelimiting enzyme of cholesterol biosynthesis; reducing LDL-C, VLDL-C and TG levels and also impart the additional effects of anti-inflammatory, antithrombotic properties to the atherosclerosis vascular disease and improve endothelial function. ${ }^{8}$ However, the prolonged treatment of such drugs have found many adverse effects like hyperuricemia, myositis, diarrhea, gastric irritation, dry skin and liver failure. ${ }^{9}$ Some of studies have suggested that the natural plant products like Trigonella foenum graecum, Murraya koenigii and Morus alba have an estrogen-like effect in the body due to the presence of phytoestrogens. ${ }^{6,9}$

Cite this article: Phatak RS, Khanwelkar CC, Matule SM, Datkhile KD, Hendre AS. Antihyperlipidemic Activity of Murraya koenigii Leaves Methanolic and Aqueous Extracts on Serum Lipid Profile of High Fat-Fructose Fed Rats. Pharmacog J. 2019;11 (4):836-41. 
Therefore, it is a need to research over traditional plant extracts to overcome possible side effects of hypolipidemic synthetic drugs.

Murraya koenigii Linn is an aromatic pubescent shrub generally known as "Kadhipatta" in India and curry leaves as common synonym. Hypolipidemic effects of this plant have been reported in several studies. The beneficial effects of Murraya koenigii leaves on HFFD induced hyperlipidemia in rats have very less reported in the recent literature. So, the present study was aimed to assess the hypolipidemic activity of Murraya koenigii leaves on the body weight, BSL and lipid profile in HFFD rat model.

\section{MATERIAL AND METHODS}

\section{Drug and chemicals}

Metformin and Atorvastatin as pure powder purchased from SigmaAldrich Ltd, India. Fructose obtained from Loba-chemie, India. Vanaspati ghee, egg yolk and coconut oil were procured from the local market. All reagents and chemicals used were of analytical grade and stored in a refrigerator at $-4^{\circ} \mathrm{C}$. The reagents were equilibrated at room temperature for $30 \mathrm{~min}$ before analysis.

\section{Collection and authentication of plant material}

Leaves of Murraya koenigii were collected from the local area of Karad in Maharashtra, India $\left(17.2760^{\circ} \mathrm{N}, 74.2003^{\circ} \mathrm{E}\right)$, certified and authenticated by Department of Botany, M. S. Shinde Mahavidyalaya, Tisangi, Kolhapur, India. The plant specimen voucher no: V03 (Ref: MHST/2016-17/28) of the plant was deposited in the herbarium. Fresh leaves were washed under tap water thoroughly; dried under shade and powdered by using a mechanical grinder.

\section{Preparation of Murraya koenigii leaves extracts}

Methanolic and aqueous extracts of Murraya koenigii leaves were prepared by soxhletation method. About $50 \mathrm{~g}$ of shade dried leaves powder of Murraya koenigii was defatted by petroleum ether; dried it then packed in a cloth bag and placed in the thistle of Soxhlet apparatus. The Soxhlet continuous extraction process was continued for 4 days till the dark brown colour of aqueous extract turned to pale yellow while in case of methanolic extract, the appearance of dark green to colourless. Collected extracts were concentrated in the vacuum rotary evaporator at Government College of Pharmacy, Karad, Maharashtra, India and dried by evaporating in hot air oven at $45^{\circ} \mathrm{C}$. Percentage yield of MEMK and AEMK were calculated with respect to the total quantity of powder used for the extraction.

\section{Acute toxicity study of extracts}

AEMK and MEMK were performed in the acute toxicity test as per OECD-423 guidelines ${ }^{10}$ for fixing the therapeutic dose. The dose of $2000 \mathrm{mg} / \mathrm{kg} \mathrm{b}$ w of AEMK and MEMK taken as a starting dose and were orally administrated to two healthy Wistar rats. $\mathrm{LD}_{50}$ was determined and $1 / 10^{\text {th }}$ of $\mathrm{LD}_{50}$ was taken as therapeutic dose for the activity.

\section{Experimental animals}

Healthy Wistar rats of either sex weighing between 100-120 g were used in the study. Animals were obtained from National Institute of Biosciences, Pune and bred in the Central Animal House, Krishna Institute of Medical Sciences, Karad, India. Animals were maintained under standard husbandry conditions at room temperature with light: dark cycle for an acclimatization period of 7 days. Experiment study protocol was compiled with the guidelines of committee for the CPCSEA for animal experimentation in laboratory and Institutional Animal Ethics Committee, Krishna Institute of Medical Sciences, Karad (Reg. No. 255/PO/2000/bc/CPCSEA) approved the study.

\section{Inclusion criteria}

Healthy Wistar rats of either sex weighing 120-200 g.

\section{Exclusion criteria}

Rats of either sex which were previously treated with any drug or extract and if infected with disease.

\section{Pilot study}

Ten healthy Wistar rats of either sex were selected; their blood samples were collected by retro-orbital puncture method; BSL and lipid profile were assessed.

\section{Experimental design}

Thirty-six healthy Wistar rats of either sex were randomly divided into six groups (six animals per group) and they had free access to water and animal diet throughout the study period.

\section{Induction of hyperlipidemia}

Hyperlipidemia in rats was induced through HFFD model. Hyperlipidemia model was developed using a high fructose $(10 \%$ fructose) added in drinking water bottle ${ }^{11}$ and high fat (vanaspati ghee: coconut oil in ratio of 3:1) mixed with an egg yolk in dough of animal food diet. ${ }^{12}$ HFFD was fed to rats of Group I to VI (Except Group III) throughout the study period of 14 weeks. Drugs or extracts in given doses were given $\mathrm{p}$. o treatment.

Group I-AEMK: Rats received HFFD and administrated AEMK-200 $\mathrm{mg} / \mathrm{kg} /$ day, p. o

Group II-MEMK: Rats received HFFD and administrated MEMK-200 $\mathrm{mg} / \mathrm{kg} /$ day, p. o

Group III-NC: Rats received normal diet and served as normal control

Group IV-MET: Rats received HFFD and administrated Metformin-50 $\mathrm{mg} / \mathrm{kg} /$ day, p. o

Group V-ATO: Rats received HFFD and administrated Atorvastatin-10 $\mathrm{mg} / \mathrm{kg} /$ day, p. o

Group VI-HC: Rats received HFFD and served as hyperlipidemia control

\section{Gravimetric analysis}

The body weight of all rats was recorded on first and final days by using digital weighing machine. Also, percent changes of body weight of all rats were calculated.

\section{Blood collection and preparation of serum}

On the last day of experimental study, all the animals were anesthetized; blood was collected by retro-orbital puncture method; centrifuged at $10000 \mathrm{rpm}$ for $10 \mathrm{~min}$; analyzed BSL and lipid profile. All animals were sacrificed by cervical decapitation at the end of study.

\section{Biochemical analysis}

TC, HDL-C and TG were measured by automatic analyzer using commercial diagnostic kit (ERBA diagnostics Mannheim $\mathrm{GmBH}$, Germany) according to the procedure described in the manufacturer's operation manual. VLDL-C and LDL-C were estimated by using Friedewald's equation. ${ }^{13}$ AIP was calculated. ${ }^{14}$ 
Parameters

VLDL

LDL

$\mathrm{Al}$

$$
\begin{gathered}
\text { Formulae } \\
\mathrm{VLDL}=\frac{\mathrm{TG}\left(\frac{\mathrm{mg}}{\mathrm{dL}}\right)}{5} \\
\mathrm{LDL}=\mathrm{TC}-(\mathrm{HDL}+\mathrm{VLDL}) \\
\mathrm{AI}=\log \left(\frac{\mathrm{TG}}{\mathrm{HDL}}\right)
\end{gathered}
$$

\section{Statistical analysis}

Data were expressed as Mean \pm SEM. Data were analyzed using Graph Pad Prism 5.0 software (Graph Pad, San Diego, CA) and two-way repeated ANOVA and Tukey's test was applied for post-hoc analysis. The value of $p<0.05$ was considered to be statistically significant.

\section{RESULTS}

\section{Percentage yield}

Percentage yield was found to be AEMK (14.35\%) and MEMK (13.75\%) with respect to the total quantity of powder used for the extraction.

\section{Acute toxicity study of extracts}

The acute toxicity study observed no mortality or any toxic reactions within $4 \mathrm{~h}$ and after 14 days by oral administration of AEMK and MEMK even at the highest dose $(2000 \mathrm{mg} / \mathrm{kg})$. The dose of $200 \mathrm{mg} / \mathrm{kg}$ was considered safe at $1 / 10^{\text {th }}$ dose of $\mathrm{LD}_{50}$ which was in agreement with report by Lanjhiyana et al. (2011). ${ }^{15}$

\section{Pilot study of BSL and lipid profile}

Body weight, BSL and lipid profile of ten rats were assessed. BSL and lipid profile were established for the normal range reference as shown in Table 1. All values are shown which is in mostly agreement with the results of study by Ahangarpour et al. (2016). ${ }^{16}$

\section{Effect of Murraya koenigii leaves extracts on body weight}

Body weight was calculated on first and final days of the experimental study period as shown in Table 2 . Extremely significant effect on body weight $(p<0.001)$ in Groups I, IV and V while no significant change were observed in Group II when compared to group VI. Percentage change in body weight was found highly significant change $(p<0.01)$ in Group I, significant change $(p<0.05)$ in Group V whereas no significant change were observed in Group II when compared to Group VI.

\section{Effect of Murraya koenigii leaves extracts on glycemic profile}

BSL was evaluated on first and final days of the experimental study period depicted in Table 3. No significant difference was found in BSL among all groups.

\section{Effect of Murraya koenigii leaves extracts on lipid profile}

Lipid profile was evaluated on the final day of the experimental study period, depicted in Table 4. Group I and II were given treatment of AEMK and MEMK respectively while Group IV and V were given treatment of standard drugs i.e., Metformin and Atorvastatin correspondingly. Group III and VI were considered as normal control and as hyperlipidemia controls respectively. Highly significant hypocholesterolemic effect $(p<0.01)$ was observed in Groups II, IV and V when compared to group VI. Group V revealed significant effect $(p<0.05)$ on TG, VLDL-C and highly significant ameliorated effect $(p<0.01)$ on HDL-C in comparison to group VI. Groups II and IV showed highly significant hypolipidemic effect $(p<0.01)$ on LDL-C ascompared to Group VI.

\section{Effect of Murraya koenigii leaves extracts on atherogenic index of plasma}

AIP was analyzed by the given formula shown in Table 5. Groups I, IV and $\mathrm{V}$ showed an extremely significant result $(p<0.001)$ while group

Table 1: Baseline values of glycemic and lipid profile of normal rats in the pilot study.

\begin{tabular}{ccccccccc}
\hline Rats & BSL $(\mathrm{mg} / \mathrm{dL})$ & $\mathrm{TC}(\mathrm{mg} / \mathrm{dL})$ & $\mathrm{TG}(\mathrm{mg} / \mathrm{dL})$ & $\mathrm{VLDL}-\mathrm{C}(\mathrm{mg} / \mathrm{dL})$ & $\mathrm{LDL}-\mathrm{C}(\mathrm{mg} / \mathrm{dL})$ & $\mathrm{HDL}-\mathrm{C}(\mathrm{mg} / \mathrm{dL})$ & AIP \\
\hline Mean & 78.2 & 56.5 & 41.71 & 8.34 & 34.5 & 13.68 & 0.17 \\
Min & 44 & 46 & 14 & 3 & 5.12 & 3 & -0.314 \\
Max & 124 & 86 & 92 & 18 & 57 & 30.7 & 0.9 \\
Range & $40-124$ & $40-90$ & $10-100$ & $2-20$ & $5-57$ & $3-30$ & $-0.3-0.9$ \\
\hline
\end{tabular}

\begin{tabular}{|c|c|c|c|}
\hline Group & $\begin{array}{l}\text { Initial body weight } \\
\text { (g on first day) }\end{array}$ & $\begin{array}{l}\text { Final body weight } \\
\text { (g on last day) }\end{array}$ & $\begin{array}{c}\text { Percentage change in } \\
\text { body weight }\end{array}$ \\
\hline I-AEMK & $122.83 \pm 10.45$ & $137.16 \pm 12.45^{* * *}$ & $10.17 \pm 01.41^{* *}$ \\
\hline II-MEMK & $112.00 \pm 17.54$ & $209.33 \pm 06.25^{\mathrm{NS}}$ & $45.47 \pm 10.02^{\mathrm{NS}}$ \\
\hline III-NC & $108.00 \pm 07.38$ & $200.83 \pm 04.93$ & $45.60 \pm 04.98$ \\
\hline IV-MET & $104.33 \pm 04.47$ & $167.83 \pm 04.49^{* * *}$ & $37.44 \pm 03.77$ \\
\hline V-ATO & $137.00 \pm 10.82$ & $169.83 \pm 05.85^{* * *}$ & $18.02 \pm 08.80^{*}$ \\
\hline VI-HC & $120.33 \pm 08.62$ & $226.16 \pm 08.69$ & $46.92 \pm 02.64$ \\
\hline \multirow{2}{*}{ ANOVA } & 1.248 & 18.353 & 6.732 \\
\hline & 0.3119 & $<0.0001^{* * *}$ & 0.0003 \\
\hline
\end{tabular}

BW-Body weight, BSL-Blood sugar level, TC-Total cholesterol, TG-Triglycerides, LDL-C-Low density lipoprotein cholesterol, HDL-C-High density lipoprotein cholesterol, VLDL-C-Very Low-density lipoprotein cholesterol, AIP-Atherogenic index of plasma.

Table 2: Effect of Murraya koenigii leaves on body weight in HFFD fed rats.

Values are expressed in Mean \pm SEM, Number of animals $=6$, NS- Not significant, ${ }^{* * *}-p<0.001,{ }^{*}$ - $p<0.01$, ${ }^{*}-p<0.05$ (Comparison with VI), ATO- Atorvastatin (10 mg/kg/day), MET- Metformin (50 mg/kg/day), AEMK- Aqueous extract of Murraya koenigii leaves (200 mg/kg/day), MEMK -Methanolic extract of Murraya koenigii leaves (200 mg/kg/day). 
Table 3: Effect of Murraya koenigii leaves on glycemic profile in HFFD fed rats.

\begin{tabular}{|c|c|c|c|}
\hline \multicolumn{2}{|c|}{ Group } & BSL (mg/dL on first day) & BSL (mg/dL on last day) \\
\hline \multicolumn{2}{|c|}{ I-AEMK } & $70.33 \pm 01.92$ & $88.83 \pm 09.12$ \\
\hline \multicolumn{2}{|c|}{ II-MEMK } & $80.00 \pm 01.77$ & $73.00 \pm 05.37$ \\
\hline \multicolumn{2}{|c|}{ III-NC } & $73.66 \pm 01.22$ & $74.83 \pm 07.01$ \\
\hline \multicolumn{2}{|c|}{ IV-MET } & $75.50 \pm 02.26$ & $99.83 \pm 06.01$ \\
\hline \multicolumn{2}{|c|}{ V-ATO } & $74.33 \pm 01.68$ & $84.00 \pm 15.14$ \\
\hline \multicolumn{2}{|c|}{ VI-HC } & $76.33 \pm 04.48$ & $88.00 \pm 05.82$ \\
\hline \multirow{2}{*}{ ANOVA } & $\mathbf{F}$ & 1.681 & 6.732 \\
\hline & $\mathbf{p}$ & 0.1697 & 0.0003 \\
\hline
\end{tabular}

Values are expressed in Mean \pm SEM, Number of animals $=6$, NS- Not significant, ATOAtorvastatin $(10 \mathrm{mg} / \mathrm{kg} /$ day), MET- Metformin (50 mg/kg/day), AEMK- Aqueous extract of Murraya koenigii leaves (200 mg/kg/day), MEMK -Methanolic extract of Murraya koenigii leaves (200 mg/kg/day).

Table 4: Effect of Murraya koenigii leaves on lipid profile in HFFD fed rats.

\begin{tabular}{|c|c|c|c|c|c|c|}
\hline \multicolumn{2}{|c|}{ Group } & $\begin{array}{c}\mathrm{TC} \\
(\mathrm{mg} / \mathrm{dL})\end{array}$ & $\begin{array}{c}\text { TG } \\
(\mathrm{mg} / \mathrm{dL})\end{array}$ & VLDL-C (mg/dL) & LDL-C (mg/dL) & $\mathrm{HDL}-\mathrm{C}(\mathrm{mg} / \mathrm{dL})$ \\
\hline \multicolumn{2}{|c|}{ I-AEMK } & $62.16 \pm 05.56^{\mathrm{NS}}$ & $53.66 \pm 12.90^{\mathrm{NS}}$ & $10.73 \pm 02.58^{\mathrm{NS}}$ & $42.26 \pm 06.17^{\mathrm{NS}}$ & $09.16 \pm 02.46^{\mathrm{NS}}$ \\
\hline \multicolumn{2}{|c|}{ II-MEMK } & $53.83 \pm 04.88^{* *}$ & $70.50 \pm 07.71^{\mathrm{NS}}$ & $14.10 \pm 01.54^{\mathrm{NS}}$ & $27.90 \pm 03.24^{* *}$ & $11.83 \pm 02.46^{\mathrm{NS}}$ \\
\hline \multicolumn{2}{|c|}{ III-NC } & $56.83 \pm 03.37$ & $71.33 \pm 14.41$ & $14.26 \pm 02.88$ & $38.35 \pm 05.91$ & $04.21 \pm 01.16$ \\
\hline \multicolumn{2}{|c|}{ IV-MET } & $53.00 \pm 06.00^{* *}$ & $65.16 \pm 14.51^{\mathrm{NS}}$ & $13.03 \pm 02.90^{\mathrm{NS}}$ & $24.46 \pm 03.34^{* *}$ & $15.50 \pm 02.26^{\mathrm{NS}}$ \\
\hline \multicolumn{2}{|c|}{ V-ATO } & $55.16 \pm 03.15^{* *}$ & $32.16 \pm 07.08^{*}$ & $06.43 \pm 01.41^{*}$ & $39.73 \pm 04.81^{\mathrm{NS}}$ & $09.00 \pm 02.50^{* *}$ \\
\hline \multicolumn{2}{|c|}{ VI-HC } & $79.33 \pm 03.44$ & $102.50 \pm 20.98$ & $20.50 \pm 04.19$ & $54.86 \pm 03.92$ & $03.96 \pm 00.30$ \\
\hline \multirow{2}{*}{ ANOVA } & $\mathbf{F}$ & 4.827 & 2.831 & 2.831 & 5.315 & 4.726 \\
\hline & $\mathbf{p}$ & 0.0023 & 0.0328 & 0.0328 & 0.0013 & 0.0027 \\
\hline
\end{tabular}

Values are expressed in Mean \pm SEM, Number of animals $=6$, NS- Not significant, ${ }^{* * *}-\mathrm{p}<0.001,{ }^{* *}-\mathrm{p}<0.01,{ }^{*}-\mathrm{p}<0.05($ Comparison with VI) ATO- Atorvastatin (10 mg/kg/day), MET- Metformin (50 mg/kg/day), AEMK- Aqueous extract of Murraya koenigii leaves $(200 \mathrm{mg} / \mathrm{kg} /$ day), MEMK -Methanolic extract of Murraya koenigii leaves (200 mg/kg/day).

Table 5: Effect of Murraya koenigii leaves on atherogenic index of plasma in HFFD fed rats.

\begin{tabular}{|c|c|c|}
\hline \multicolumn{2}{|c|}{ Group } & AIP \\
\hline \multicolumn{2}{|c|}{ I-AEMK } & $0.435 \pm 0.09^{* * x}$ \\
\hline \multicolumn{2}{|c|}{ II-MEMK } & $0.488 \pm 0.12^{* *}$ \\
\hline \multicolumn{2}{|c|}{ III-NC } & $0.994 \pm 0.19$ \\
\hline \multicolumn{2}{|c|}{ IV-MET } & $0.219 \pm 0.15^{x+x}$ \\
\hline \multicolumn{2}{|c|}{ V-ATO } & $0.224 \pm 0.18^{*+x \times}$ \\
\hline \multicolumn{2}{|c|}{ VI-HC } & $1.373 \pm 0.06$ \\
\hline \multirow{2}{*}{ ANOVA } & $\mathbf{F}$ & 10.284 \\
\hline & $\mathbf{p}$ & $<0.0001$ \\
\hline
\end{tabular}

Values are expressed in Mean \pm SEM, Number of animals $=6$, NS- Not significant, ${ }^{* * *}-p<0.001,{ }^{* *}-p<0.01,{ }^{*}-p<0.05$ (Comparison with VI), ATO- Atorvastatin (10 mg/kg/day), MET- Metformin (50 mg/kg/day), AEMK- Aqueous extract of Murraya koenigii leaves (200 mg/kg/day), MEMK -Methanolic extract of Murraya koenigii leaves (200 mg/kg/day).

II exhibited significant difference $(P<0.01)$ in AIP when compared to group VI.

\section{DISCUSSION}

Fructose intake may be associated with an increased risk of diabetes, hyperlipidemia and obesity through several mechanisms and also increases body weight due to the positive energy balance. Positive energy balance is associated with higher levels of non-esterified fatty acids, reduced insulin sensitivity; increased hepatic glucose production. ${ }^{17}$ High fat fructose diet pattern has increased significantly the body weight and induced hyperlipidemia but not enhanced BSL in the present study. Our findings of the present study have shown that there was no significant change in BSL in the $1^{\text {st }}$ and $14^{\text {th }}$ days of experimental study period which is in consistency with the study reported by Lozano et al. (2016). ${ }^{18}$ Our results of the study has indicated that HFFD model does not induce hyperglycemia in the period of 14 weeks which is in agreement with the study reported by Zaman et al. (2011). ${ }^{19}$ According to study by Lozano et al. $(2016)^{18}$ have suggested that this HFFD model needs more than 6 months period to provoke hyperglycemia.

It shows similar lipid lowering effect in spite of different solvents used for extraction like chloroform, ${ }^{20}$ dichloromethane, ${ }^{21}$ ethyl acetate $^{21}$ and ethanol ${ }^{22}$ apart from aqueous and methanol extracts. Other than leaves, stem bark extract of Murraya koenigii ${ }^{23}$ has shown to exert hypolipidemic effect which is similar to that effect of leaves. Hypolipidemic effect of AEMK is in agreement with the aqueous extract of Murraya koenigii in the studies of Kesari et al. (2005), ${ }^{22}$ Upadhye et al. (2014), ${ }^{23}$ Ekoh et al. (2014), ${ }^{24}$ El-Amin et al. (2013), ${ }^{25}$ Lawal et al. (2008), ${ }^{26}$ Vinuthan et al. (2007) ${ }^{27}$ while MEMK is in conformity with the methanolic extract of this plant in study by Vinuthan et al. (2007). ${ }^{27}$ They have reported the antihyperlipidemic effect of Murraya koenigii leaves in terms of lipid profile only. 
The phytochemical constituents of Murraya koenigii have been reported for various pharmacological activities. ${ }^{28}$ Some of them have proven as potential nutraceutical for diabetes and cardioprotective activity. An extensive range of phytochemicals such as carbazole alkaloids, essential oil, carotenoids-lutein, phenolics, terpenoids, a-tocopherol, minerals, fibers, nicotinic acid, vitamin $\mathrm{C}$ etc. were reported in curry leaves. ${ }^{28}$ Based on the reports in the present study, the mechanism of antihyperlipidemic effect of Murraya koenigii could not be explained exactly. However, we suggested that higher concentration of genistein, diphenolic phytoestrogens present in Murraya koenigii might be responsible for this effect. ${ }^{3}$

Dyslipidemia is a lipid metabolic disorder characterized by elevated levels of TC, TG, LDL-C, VLDL-C and lowered level of HDL-C ${ }^{29}$ and considered as one of coronary risk factors in contributing to CVD. In the present study, both of AEMK and MEMK have showed hypolipidemic effects in HFFD-fed rats. HFFD pattern for the period of 14 weeks could be responsible to induce elevated levels of TC, TG and LDL-C in comparison to the normal control group. Both of AEMK and MEMK have exhibited an important role in lowering levels of TC and LDL-C in compared to group VI remarkably. Furthermore, the two possible mechanisms of preventing LDL oxidation explained in the hypothesis here that Murraya koenigii leaves increases HDL level by activating the enzyme, HDL-associated paraoxanase and protecting this enzyme from cell damage ${ }^{29}$ and another is as redistribution of lipoproteins due to the presence of bioactive compounds like flavonoids and phenolics. ${ }^{30} \mathrm{In}$ our previous study, Murraya koenigii leaves has proven as potent free radical scavenger in the DPPH assay ${ }^{31}$ so that bioactive compounds are involved in depleting TC levels through two possible mechanisms i.e. reducing fat absorption in the digestive system and increasing fat excretion into faeces. ${ }^{29}$

Recently, the antihyperlipidemic efficacy of curry leaves on the lipid profile of menopause women has been reported in the randomized controlled pilot study by improving HDL-C and lowering TG and LDL-C. ${ }^{28}$ However, we think this may be showed an additive effect since it is combination therapy of curry leaves with cucumber, so further extensive studies are needed to confirm this hypolipidemic activity of curry leaf as a single therapy in animal models as well as human trials. If proven in human trials, this can be used as adjuvant to the existing hypolipidemic drugs.

\section{CONCLUSION}

Results of the present study have suggested that the antihyperlipidemic activity of Murraya koenigii leaves leading to decrease serum lipid parameters mainly TC, LDL-C along with atherogenic risk is due to the presence of its bioactive compounds.

\section{ACKNOWLEDGEMENTS}

Authors express heartfelt gratitude to Honorable Chairman Dr. Suresh J. Bhosale and Research Fund Allotment Committee for providing financial assistance and facilities to the $\mathrm{Ph}$. D research project. Authors acknowledge helpfulness to Dr. Bhatalekar, Director, National Institute of Biosciences, Pune for providing animals. Authors are thankful to Dr. Ajit Sontakke, Dr. Sangita Patil and staffs of clinical biochemistry for providing assistance in the biochemical analysis.

\section{PLACE WHERE THE WORK CARRIED OUT}

Department of Genetic and Molecular Biology, Department of Pharmacology \& Department of Biochemistry, Krishna Institute of Medical Sciences, Karad-415110, Maharashtra, India.

\section{CONFLICTS OF INTEREST}

The authors declare that they have no conflicts of interest.

\section{ABBREVIATIONS}

HFFD: High Fat-Fructose Diet; AEMK: Aqueous Extract of Murraya koenigii Leaves; MEMK: Methanolic Extract of Murraya koenigii Leaves; MET: Metformin; ATO: Atorvastatin; p. o: Per Oral; TC: Total Cholesterol; TG: triglycerides; LDL-C: Low Density LipoproteinCholesterol; VLDL-C: Very Low Density Lipoprotein-Cholesterol; HDL-C: High Density Lipoprotein-Cholesterol; AIP: Atherogenic Index of Plasma; BSL: Blood Sugar Level; MetS: Metabolic Syndrome; CHD: Coronary Heart Disease; CVD: Cardiovascular Disease; SMC: Smooth Muscle Cells; SHBG: Sex Hormone Binding Globulin; HMGCoA: 3-hydroxy, 3-methylglutaryl coenzyme A; OECD: Organization for Environmental Control Development; CPSEA: Purpose of Control and Supervision of Experiments on Animals; $\mathrm{mg} / \mathrm{kg} \mathrm{b}$ w: Milligram/ Kilogram Body Weight; $\mathrm{LD}_{50}$ : Lethal Dose 50\%; SEM: Standard Error Means; ANOVA: Analysis of Variance; DPPH: 2, 2-diphenyl-1picrylhydrazyl.

\section{REFERENCES}

1. Rivera-Ramírez F, Escalona-Cardoso GN, Garduño-Siciliano L, GalavizHernández C, Paniagua-Castro N. Antiobesity and hypoglycaemic effects of aqueous extract of Ibervillea sonorae in mice fed a high-fat diet with fructose. J Biomed Biotechnol. 2011;6.

2. Maithilikarpagaselvi N, Sridhar MG, Swaminathan RP, Sripradha R, Badhe B Curcumin inhibits hyperlipidemia and hepatic fat accumulation in high-fructosefed male Wistar rats. Pharm Biol. 2016;54(12):2857-63.

3. Ramadan AA, Afifi NA, Erian EY, Saleh DO, Sedik AA. Beneficial Effect of Trigonelline on the metabolic changes associated with insulin resistance in rats. World J Pharm Pharm Sci. 2015;5(2):1238-50.

4. Vengala N. Antihyperlipidemic activity of flax lignan concentrate in nicotinamide-streptozotocin induced diabetic hyperlipidemia rats. Res Rev Biosci. 2017;12(2):120.

5. Fledderus JO, van Oostrom $O$, de Kleijn DP, den Ouden K, Penders AF, Gremmels $\mathrm{H}$, de Bree P, Verhaar MC. Increased amount of bone marrowderived smooth muscle-like cells and accelerated atherosclerosis in diabetic apoE-deficient mice. Atherosclerosis. 2013;226(2):341-7.

6. Nandini MS, Veena T, Swamy MN. Effect of extracts of Murraya koenigii Spreng. and Morus alba linn. on the age of attainment of puberty and ovarian folliculogenesis in rats. J Basic Clin Pharm. 2010;1(4):203-7.

7. Bhupathy $P$, Haines $C D$, Leinwand LA. Influence of sex hormones and phytoestrogens on heart disease in men and women. Women's Health (Lond Engl). 2010;6:77-95.

8. Cavallini DC, Bedani $R$, Bomdespacho LO, Vendramini RC Rossi EA Effects of probiotic bacteria, isoflavones and simvastatin on lipid profile and atherosclerosis in cholesterol-fed rabbits: a randomized double-blind study. Lipids Health Dis. 2009;8:1

9. Takkella N, Konuri A, Kishore A, Rai KS, Bhat KMR. Role of cholinedocosahexaenoic acid and Trigonella foenum graecum seed extract on ovariectomy induced dyslipidemia and oxidative stress in rat model. J Krishna Inst Med Sci Univ. 2018;7(1):1-7.

10. OECD/OCDE. Acute Oral Toxicity-Acute Toxic Class Method. OECD Guidel Test Chem. 2001;423:1-14.

11. Munshi RP, Joshi SG, Rane BN. Development of an experimental diet model in rats to study hyperlipidemia and insulin resistance, markers for coronary heart disease. Indian J Pharmacol. 2014;46(3):270-6.

12. Nugroho AE, Andrie M, Warditiani NK, Siswanto E, Pramono S, Lukitaningsih E. Antidiabetic and antihiperlipidemic effect of Andrographis paniculata (Burm. f.) Nees and andrographolide in high-fructose-fat-fed rats. Indian J Pharmacol. 2012;44(3):377-81.

13. Friedewald WT, Levy RI, Fredrickson DS. Estimation of the concentration of low-density lipoprotein cholesterol in plasma, without use of the preparative ultracentrifuge. Clin Chem. 1972;18(6):499-502.

14. Niroumand $S$, Khajedaluee $M$, Khadem-Rezaiyan $M$, Abrishami $M$, Juya $M$, Khodaee G, Dadgarmoghaddam M. Atherogenic Index of Plasma (AIP): A marker of cardiovascular disease. Med J Islam Repub Iran. 2015;29:240.

15. Lanjhiyana S, Garabadu D, Ahirwar D, Bigoniya P, Rana AC, KC Patra, et al. Hypoglycemic activity studies on root extracts of Murraya koenigii root in Alloxan-induced diabetic rats. J Nat Prod Plant Resour. 2011;1(2):91-104. 
16. Ahangarpour A, Ali-Akbari FR, Mohaghegh SM, Asadinia E. Effects of Arctium lappa aqueous extract on lipid profile and hepatic enzyme levels of sucroseinduced metabolic syndrome in female rats. Braz J Pharm Sci. 2016;52(3):42531.

17. Ahangarpour A, Mohammadian M, Dianat M. Antidiabetic effect of hydroalcoholic Urtica dioica leaf extract in male rats with fructose-induced insulin resistance. Iran J Med Sci. 2012;37(3):181-6.

18. Lozano I, Van der Werf R, Bietiger W, Seyfritz E, Peronet C, Pinget M, et al. High-fructose and high-fat diet-induced disorders in rats: impact on diabetes risk, hepatic and vascular complications. Nutr Metab (Lond). 2016;13:15.

19. Bhopal CV, Buchineni M, Kudagi BL, Pathapati RM, Haritha M, Anjani DN. Hypolipidemic activity of Murraya koenigii in alloxan induced diabetic rats. Pharma Inno J. 2016;5(5):101-3.

20. Birari R, Javia V, Bhutani KK. Antiobesity and lipid lowering effects of Murraya koenigii (L.) Spreng leaves extracts and mahanimbine on high fat diet induced obese rats. Fitoterapia. 2010;81(8):1129-33.

21. Tembhurne SV, Sakarkar DM. Beneficial effects of ethanolic extract of Murraya koenigii (Linn) leaves in cognitive deficit aged mice involving possible anticholinesterase and cholesterol lowering mechanism. Int J PharmTech Res. 2010;2(1):181-8.

22. Kesari AN, Kesari S, Singh SK, Gupta RK, Watal G. Studies on the glycemic and lipidemic effect of Murraya koenigii in experimental animals. J Ethnopharmacol. 2007;112(2):305-11.

23. Upadhye M, Pujari R, Dhane V, Anap S, Chanshetti R. Antidiabetic effect of aqueous extract of Murraya koenigii (Linn) stem bark. Invent ImpactEthnopharmacol. 2014.
24. Ekoh SN, Akubugwo El, Ude VC, Edwin N. Anti-hyperglycemic and antihyperlipidemic effect of spices (Thymus vulgaris, Murraya koenigii, Ocimum gratissimum and Piper guineense) in alloxan-induced diabetic rats. Int J Biosci. 2014;4(2):179-87.

25. El-Amin M, Virk P, Elobeid MA, Almarhoon ZM, Hassan ZK, Omer SA, et al Anti-diabetic effect of Murraya koenigii $(L)$ and Olea europaea $(L)$ leaf extracts on streptozotocin induced diabetic rats. Pak J Pharm Sci. 2013;26(2):359-65.

26. Lawal H, Atiku M, Khelpai D, Wannang N. Hypoglycaemic and hypolipidaemic effects of the aqueous leaf extract of Murraya koenigii in normal and alloxandiabetic rats. Niger J Physiol Sci. 2008;23(1-2):37-40.

27. Vinuthan MK, Girish Kumar V, Ravindra JP, Gupta PSP, Arun SJ. Changes in the blood lipid profile after administration of Murraya koenigii Spreng (curry leaf) extracts in the normal Sprague Dawley rats. Indian J Anim Res. 2007;41(3):2235 .

28. Molly J, Edison S, Vijajaraghavan R, Ajith TA. Effect of curry leaves and cucumber fruit on lipid profile in menopausal women with hyperlipidaemia: a randomized controlled pilot study. Int J Clin Trials. 2017;4(1):7-13.

29. Thomas SZ, Pertiwi D, Bagus SA, Nuri S, Jelita BEM, Alfiza NS. Effect of tender coconut water on blood lipid levels in hight fat diet fed male rats. J Krishna Inst Med Sci Univ. 2017;6(2):63-8.

30. Patel SS, Goyal RK, Shah RS, Tirgar PR, Jadav PD. Experimental study on effect of hydroalcoholic extract of Emblica officinalis fruits on glucose homeostasis and metabolic parameters. Ayu. 2013;34(4):440-4

31. Phatak RS, Khanwelkar CC, Datkhile KD, Hendre AS. Investigation of antioxidant and antidiabetic activities of Murraya koenigii leaves methanolic and aqueous extract by in-vitro methods. Int J Res Pharm Sci. 2018;9(4):1460-4.

\section{SUMMARY}

Leaves of Murraya koenigii were collected, air dried under shade, powdered by mechanical grinder. Leaves powder was macerated in a conical flask by petroleum ether to remove fats. Methanolic and aqueous extracts of leaves were prepared in the Soxhlet apparatus separately. HFFD was fed to rats in the period of 3 months; treated with Murraya koenigii leaves extracts and blood samples were collected through retro-orbital method on the last day of experimental study. BW, BSL and lipid profile were analyzed. Hypolipidemic effect was proven so it may be useful as a nutraceutical.

Cite this article: Phatak RS, Khanwelkar CC, Matule SM, Datkhile KD, Hendre AS. Antihyperlipidemic Activity of Murraya koenigii Leaves Methanolic and Aqueous Extracts on Serum Lipid Profile of High Fat-Fructose Fed Rats. Pharmacog J. 2019;11(4):836-41. 